\title{
Implementation of Molecular RHD Typing at Two Blood Transfusion Institutes from Southeastern Europe
}

\author{
Gordana Guzijan a, b Snezana Jovanovic Srzentic ${ }^{c}$ Natasa Pavlovic Jankovic ${ }^{c}$ \\ Iva Djilas ${ }^{c}$ Marko Lilićd \\ a Institute for Transfusion Medicine of Republika Srpska, Banja Luka, Bosnia-Herzegovina; b Medical Faculty, \\ University of Banja Luka, Banja Luka, Bosnia-Herzegovina; 'Blood Transfusion Institute of Serbia, Belgrade, Serbia; \\ d Josip Juraj Strossmayer University of Osijek, Osijek, Croatia
}

\section{Keywords}

Molecular blood group typing $\cdot$ PCR $\cdot$ Rh phenotyping ·

RHD gene $\cdot$ RHD variants

\begin{abstract}
Introduction: Determination of RhD variants in blood donors, pregnant women, and newborns is important for transfusion strategies, in order to prevent RhD alloimmunisation and hemolytic disease of fetuses and newborns. Implementation of molecular RHD typing in two transfusion institutes is presented in this article, from Banja Luka (Bosnia and Herzegovina) and Belgrade (Serbia). Study Design and Methods: Blood donors' RhD was checked by direct agglutination assays (tube) and indirect antiglobulin test (gel). Molecular RHD typing was performed by PCR-SSP with fluorometric signal detection in both centres. Donors were selected by weak RhD serological reactivity (Banja Luka, 85 samples; Belgrade, 62 samples) or serologically RhD-negative C/E-positive results (Banja Luka, 92 samples; Belgrade, 61 samples). $\boldsymbol{R e}$ sults: Among serologically determined weak $D$ donors from the institute from Banja Luka, weak D type 3 was the most frequent (58.8\%), followed by type 1 (35.3\%) and DNB (1.2\%), whereas results obtained at the Belgrade institute were distributed between weak $D$ type 1 (41.9\%), type 3 (30.7\%), type $14(6.5 \%)$, type $15(1.6 \%)$, and DNB with anti-D (1.6\%). In $17.7 \%$ of serologically typed weak D samples from the Belgrade institute, the molecular typing result was standard D.
\end{abstract}

Additionally, RHD presence was detected in $9.8 \%$ of serologically RhD-negative, C/E-positive samples from both institutes. Conclusion: Rh molecular testing was successfully implemented in both blood transfusion institutes in Banja Luka and Belgrade. This study proved the efficiency of serological algorithms for weak $D$, as well as the presence of the RHD gene among serologically tested RhD-negative, C/E-positive samples.

(c) 2019 S. Karger AG, Basel

\section{Introduction}

The Rh (Rhesus) blood group system (International Society of Blood Transfusion No. ISBT 004) is one of the most polymorphic gene systems in human beings. Together with ABO (ISBT 001), it is the most clinically significant blood group system for transfusion medicine because of its implications in transfusion reactions and hemolytic disease of the fetus and newborn. RHD and RHCE are pairs of highly homologous genes which encode all the antigens of the Rh system and their number is more than 50 - as of June 2018, ISBT lists $55 \mathrm{Rh}$ antigens [1]. These two genes share $93.8 \%$ homology of all introns and coding exons $[2,3]$. They are closely linked on chromosome $1 \mathrm{p} 3611$, but lay in opposite orientation: $5^{\prime}-R H D-3^{\prime}-3^{\prime}-$ RHCE-5' [4]. Both genes consist of 10 exons that encode two 417-amino acid polypeptides, $\mathrm{RhD}$ and $\mathrm{RhCE}$, with

\section{KARGER}

(C) 2019 S. Karger AG, Basel 
the $\mathrm{N}$-terminal methionine being cleaved from the mature proteins $[5,6]$. The $\mathrm{RhD}$ and RhCE proteins differ by 31 or 35 amino acids, depending on the RHCE allele. They are hydrophobic molecules and span the red cell membrane 12 times, with internal N- and C-termini and 6 external loops [7]. The most important antigen of the $\mathrm{Rh}$ system is $\mathrm{RhD}$, due to its immunogenicity. The frequency of people with an $\mathrm{RhD}$-positive phenotype varies from about $85 \%$ in Caucasians, to nearly $95 \%$ in sub-Saharan Africa, and more than 99.5\% in eastern Asia [8]. The RhDnegative phenotype in Caucasians usually stems from the complete deletion of $\mathrm{RhD}$ protein, which explains the high immunogenicity of the $\mathrm{RhD}$ antigen. The most common genotypes globally are homozygosity or compound heterozygosity for an $R H D$ deletion, inactivated $R H D^{*} \Psi$ gene, or hybrid genes $D-C E-D[3]$. To date, $R H D$ zygosity has been resolved, $\mathrm{RhD}$ epitopes have been mapped, and many $\mathrm{RhD}$ variants with altered $\mathrm{D}$ antigens have been identified, but no absolute correlation between phenotypic expression and clinical relevance of $R H D$ alleles has been resolved [9]. More than 200 RHD alleles have been categorised considering their phenotypic relationship into molecular variations of partial $\mathrm{D}$, weak $\mathrm{D}$ types, $\mathrm{DEL}$, and non-function alleles $[8,10]$. Two types of molecular mechanisms mostly occur for D variants: (a) one or several nucleotide changes in the $R H D$ gene, resulting in amino acid substitutions in $\mathrm{RhD}$ protein, and (b) genetic recombination, probably as a result of gene conversion, with the possibility of appearance of an $R H D^{*} D-C E-D$ variant, in which a portion of the $R H D$ gene is replaced by the corresponding part from the RHCE gene [3].

Problems in immunohematological testing occur when blood donors express trace amounts of RhD antigen and can be wrongly typed as $\mathrm{RhD}$ negative. This can result in inappropriate transfusion therapy and increased risk of alloimmunisation in patients receiving blood components from these donors [11]. In addition, there are several valuable serological methods for $\mathrm{RhD}$ typing, as well as test reagents with various sensitivity [12-16]. Immunohematological tests, such as the enzyme test, indirect antiglobulin test, and adsorption/elution techniques, are suitable for the detection of some weak $\mathrm{D}$ phenotypes. However, there are some weak and partial D antigens that could not be detected by routine serological techniques. $\mathrm{D}$-negative patients transfused with red blood cells (RBCs) which carry these variant epitopes may develop anti-D alloantibody. Anti-D alloimmunisations in patients with weak D types 1-3 and 4.0/4.1 have not been observed. These are the most common weak $\mathrm{D}$ variants and together represent more than $93 \%$ of all weak D types in Caucasian populations. Transfusion recipients and pregnant women who carry these weak $\mathrm{D}$ types may be safely transfused with $\mathrm{RhD}$-positive blood. This may save up to $5 \%$ of RhD-negative units, which should be desig-
Table 1. RHD phenotype distribution after molecular testing of initially serologically determined weak D donors from ITMRS

\begin{tabular}{lclll}
\hline $\begin{array}{l}\text { Rh phenotype } \\
\text { (serology) }\end{array}$ & $\begin{array}{l}\text { CcDwee, } \\
n(\%)\end{array}$ & $\begin{array}{l}\text { CCDwee, } \\
n(\%)\end{array}$ & $\begin{array}{l}\text { ccDwEe, } \\
n(\%)\end{array}$ & $\begin{array}{l}\text { Total, } \\
n(\%)\end{array}$ \\
\hline Weak D type 1 & $29(34.1)$ & $1(1.2)$ & $0(0.0)$ & $30(35.3)$ \\
Weak D type 3 & $49(57.7)$ & $1(1.2)$ & $0(0.0)$ & $50(58.8)$ \\
DNB & $0(0.0)$ & $1(1.2)$ & $0(0.0)$ & $1(1.2)$ \\
Other weak D types & $1(1.2)$ & $0(0.0)$ & $3(3.5)$ & $4(4.7)$ \\
\hline Total & $79(92.9)$ & $3(3.5)$ & $3(3.5)$ & $85(100.0)$ \\
\hline
\end{tabular}

nated and reserved for patients who will benefit from RhD-negative blood components $[17,18]$.

$R H D$ typing of apparently $\mathrm{RhD}$-negative blood donors by molecular methods is generally still not in common use worldwide. Some literature shows that RHD genotyping should be recommended primarily for D-negative Cor E-positive donors, taking into consideration the results of some authors who found weak D or DEL phenotypes in serologically typed D-negative and C/E-positive individuals only by $R H D$ molecular typing $[19,20]$.

Considering technical difficulties and the clinical importance of the Rh system in transfusion medicine and hemolytic disease of the newborn, it seems crucial and should be encouraged to determine frequencies of $R H D$ variants in every population. The aims of this study were: (1) to introduce an optimal testing algorithm for future routine use at both the Institute for Transfusion Medicine of Republika Srpska (ITMRS), Banja Luka, Bosnia and Herzegovina, and Blood Transfusion Institute of Serbia (BTIS), Belgrade, Serbia; (2) to confirm and classify RHD variants in the pool of blood donors who were serologically identified as weak D, with molecular assays; (3) to identify possible $R H D$ variants in serologically $\mathrm{D}-, \mathrm{C} / \mathrm{E}+$ individuals; (4) to identify possible $R H D$ variants in serologically D-positive individuals with anti-D antibodies; and (5) to compare results obtained by serological and molecular methods. By defining these aims, we strive to improve $\mathrm{RhD}$ testing, with blood donors, pregnant women, and patients in mind.

\section{Materials and Methods}

\section{Subjects}

The ITMRS from Banja Luka enrolled 177 subjects into this study (85 initially weak RhD and $92 \mathrm{RhD}$ negative), while the BTIS in Belgrade had 123 individual samples (61 initially weak RhD, 1 typed as $\mathrm{D}$ positive with anti-D antibody, and 61 were $\mathrm{RhD}$ negative).

Criteria and Serological Methods

The criteria for the selection of study participants were:

(a) for serologically weak D samples (85 samples from ITMRS and 61 from BTIS): 
Table 2. $R H D$ phenotype distribution after molecular testing of initially serologically determined weak D donors and RhD-positive individuals with anti-D antibodies from BTIS

\begin{tabular}{lllllll}
\hline $\begin{array}{l}\text { Rh phenotype } \\
\text { (serology) }\end{array}$ & $\begin{array}{l}\text { CcDwee, } \\
n(\%)\end{array}$ & $\begin{array}{l}\text { CCDwee, } \\
n(\%)\end{array}$ & $\begin{array}{l}\text { ccDwEe, } \\
n(\%)\end{array}$ & $\begin{array}{l}\text { CcDwEe, } \\
n(\%)\end{array}$ & $\begin{array}{l}\text { CcDee+ } \\
\text { anti-D, } n(\%)\end{array}$ & $\begin{array}{l}\text { Total, } \\
n(\%)\end{array}$ \\
\hline Weak D type 1 & $23(37.1)$ & $0(0.0)$ & $1(1.6)$ & $2(3.2)$ & $0(0.0)$ & $26(41.9)$ \\
Weak D type 3 & $18(29.0)$ & $1(1.6)$ & $0(0.0)$ & $0(0.0)$ & $0(0.0)$ & $19(30.7)$ \\
Weak D type 14 & $0(0.0)$ & $0(0.0)$ & $4(6.5)$ & $0(0.0)$ & $0(0.0)$ & $4(6.5)$ \\
Weak D type 15 & $0(0.0)$ & $0(0.0)$ & $1(1.6)$ & $0(0.0)$ & $0(0.0)$ & $1(1.6)$ \\
Presumably D & $5(8.1)$ & $5(8.1)$ & $1(1.6)$ & $0(0.0)$ & $0(0.0)$ & $11(17.7)$ \\
DNB & $0(0.0)$ & $0(0.0)$ & $0(0.0)$ & $0(0.0)$ & $1(1.6)$ & $1(1.6)$ \\
\hline Total & $46(74.2)$ & $6(9.7)$ & $7(11.3)$ & $2(3.2)$ & $1(1.6)$ & $62(100.0)$ \\
\hline
\end{tabular}

- blood donors with direct agglutination of $\leq 2+$, performed by:

- tube method using anti-D monoclonal IgM/IgG, anti-D blend (TH-28/MS-36, anti-D blend 175 2-415 1E4, CE Immunodiagnostika, Germany) at ITMRS,

- tube method using anti-D monoclonal IgM/IgG (CE Immunodiagnostika, Sanquin) at BTIS, as well as anti-D performed in house;

- blood samples with direct agglutination of $\leq 2+$, using the gel method and ID-cards "DiaClon ABO/Rh for Donors" (monoclonal anti-D:ESD-1M, 175-2, Bio-Rad, USA) and at the same time agglutination of $\leq 3+$ using verification of $\mathrm{D}$ weak by indirect antiglobulin test using ID-cards (clone ESD1, Bio-Rad) at both institutes;

- suspect variant D types obtained by:

- D-Screen panel (Diagast, France) by tube method at ITMRS

- ID-PartialRhD Typing Set (Bio-Rad) by gel method at BTIS;

(b) donors serologically determined as $\mathrm{D}-, \mathrm{C}+$, and/or E+ at both centres ( 92 samples from ITMRS and 61 from BTIS);

(c) the presence of anti-D in plasma of D-positive blood samples (1 sample from BTIS).

In serologically $\mathrm{D}-, \mathrm{C} / \mathrm{E}+$ individuals from both centres, $\mathrm{D}$ antigen was later re-evaluated in BTIS by adsorption of human polyclonal anti-D antibodies (source: anti-D test sera of human origin, in-house production, department for production of diagnostic test reagents at BTIS) and subsequent acid elution (DiaCidel, for acid elution of serological antibodies, Bio-Rad) for further antibody identification [21]. Anti-D antibodies were detected by gel method using $\mathrm{NaCl}$ and Liss/Coombs ID-cards by ID-DiaCell IP-IIP-IIP and IDDiaCell I-II-III screening test red cells (Bio-Rad). Antibody specificity was determined using ID-DiaPanel P and ID-DiaPanel (Bio-Rad).

\section{Molecular Biology}

DNA Isolation Methods

At ITMRS, DNA was manually extracted from $200 \mu \mathrm{L}$ of EDTA blood from each participating donor using the Ready DNA Isolation Spin kit (Inno-Train Diagnostik, Germany). At BTIS, DNA was manually extracted from $200 \mu \mathrm{L}$ of EDTA blood from single donors using the GeneJET Whole Blood Genomic DNA Purification Mini Kit (Thermo Scientific, USA) or PureLink Genomic DNA Mini Kit (Life Technologies, USA). Additionally, extracted DNA was quantified using the fluorometric method (Qubit dsDNA BR Assay Kit, Life Technologies) according to the manufacturer's instructions.

PCR Methods

Samples from both institutes were investigated by $R H D$ exon scanning, detection of $R H C c E e$, testing for weak D types $1-5,11$, 15 , and 17 , and testing for RHD DEL alleles using commercially available genotyping kits (RBC-FluoGene, Inno-Train Diagnostik) based on PCR-SSP (PCR using sequence-specific primers) with fluorometric signal detection (by FluoVista instrument, Inno-Train Diagnostik) and according to the manufacturer's instructions with accompanying dedicated software for data evaluation. In addition, all serologically D-negative samples from ITMRS were initially screened for the presence of $R H D$ exons 3, 5, and 10 by the same molecular platform as described above using the commercial DScreen kit (Inno-Train Diagnostik).

\section{Confirmation}

DNB and weak D type 15 samples together with 1 of 4 weak D type 14 samples from BTIS were afterwards confirmed as such at the Blood Transfusion Centre of Slovenia with other commercial genotyping kits (RBC-Ready Gene, Inno-Train Diagnostik) based on PCR-SSP and signal detection by agarose gel electrophoresis according to the manufacturer's instructions.

\section{Results}

Serologically determined weak D expressions at both institutes were resolved by DNA typing, the results of which are specified in Tables 1 and 2, for samples from ITMRS and BTIS, respectively. Four samples from ITMRS which were not differentiated by molecular typing into specific weak D types are still to be resolved, but were definitely determined as an $R H D$ variant by Fluogene kits. Samples typed as DNB were found at both ITMRS and BTIS, with 1 sample from each institute. The DNB sample from BTIS had a CcDee phenotype and was taken from a pregnant woman with anti-D antibody present in the serum. In contrast, the DNB sample from ITMRS, with a CCDee phenotype, was taken from a female blood donor but had no anti-D in the serum.

Initially, serologically determined $\mathrm{RhD}$-negative donors were deciphered by molecular testing, the results of which are illustrated in Tables 3 and 4, for samples from ITMRS and BTIS, respectively. Four out of 9 determined $D$ variant types from ITMRS were typed as weak D type 11 , 2 samples were typed as weak D type 1 , and 1 sample as weak D type 3 - all of them had serologically determined 
Table 3. Distribution of $R H D$ variants after molecular testing of initially serologically RhD-negative donors from ITMRS

\begin{tabular}{|c|c|c|c|c|c|}
\hline \multirow{2}{*}{$\begin{array}{l}\text { Rh phenotype } \\
\text { (serology) }\end{array}$} & \multirow{2}{*}{$\begin{array}{l}\text { No presence of RHD } \\
\text { confirmed, } n(\%)\end{array}$} & \multicolumn{3}{|l|}{$R H D$ variants } & \multirow{2}{*}{$\begin{array}{l}\text { Total, } \\
n(\%)\end{array}$} \\
\hline & & total quantity, $n(\%)$ & specification & quantity, $n$ & \\
\hline Ccddee & $56(60.9)$ & $7(7.6)$ & $\begin{array}{l}\text { weak D type } 11 \\
\text { weak D type } 1 \\
\text { weak D type } 3\end{array}$ & $\begin{array}{l}4 \\
2 \\
1\end{array}$ & $63(68.5)$ \\
\hline CcddEe & $3(3.3)$ & $0(0.0)$ & - & - & $3(3.3)$ \\
\hline ccddEe & $22(23.9)$ & $0(0.0)$ & - & - & $22(23.9)$ \\
\hline CCddee & $2(2.2)$ & $0(0.0)$ & - & - & $2(2.2)$ \\
\hline $\begin{array}{l}\text { RhD-negative, C/E } \\
\text { not specified }\end{array}$ & $0(0.0)$ & $2(2.2)$ & \multicolumn{2}{|c|}{$\begin{array}{l}\text { not specified by utilised } \\
\text { kits, } D \text {-screen positive }\end{array}$} & $2(2.2)$ \\
\hline Total & $83(90.2)$ & $9(9.8)$ & & & $92(100.0)$ \\
\hline
\end{tabular}

Table 4. Distribution of $R H D$ variants after molecular testing of initially serologically RhD-negative donors from BTIS

\begin{tabular}{|c|c|c|c|c|c|}
\hline \multirow{2}{*}{$\begin{array}{l}\text { Rh phenotype } \\
\text { (serology) }\end{array}$} & \multirow{2}{*}{$\begin{array}{l}\text { No presence of } R H D \\
\text { confirmed, } n(\%)\end{array}$} & \multicolumn{3}{|l|}{$R H D$ variants } & \multirow{2}{*}{$\begin{array}{l}\text { Total, } \\
n(\%)\end{array}$} \\
\hline & & total quantity, $n(\%)$ & specification & quantity, $n$ & \\
\hline Ccddee & $39(63.9)$ & $1(1.6)$ & weak D type 11 & 1 & $40(65.6)$ \\
\hline CcddEe & $2(3.3)$ & $1(1.6)$ & weak D type 11 & 1 & $3(4.9)$ \\
\hline \multirow[t]{2}{*}{ ccddEe } & $11(18.0)$ & $3(4.9)$ & weak D type 2 & 1 & $14(23.0)$ \\
\hline & & & weak D type 15 & 2 & \\
\hline CCddee & $2(3.3)$ & $1(1.6)$ & D-CE(2-9)-D & 1 & $3(4.9)$ \\
\hline ccddEE & $1(1.6)$ & $0(0.0)$ & - & - & $1(1.6)$ \\
\hline Total & $55(90.2)$ & $6(9.8)$ & & & $61(100.0)$ \\
\hline
\end{tabular}

phenotype Ccddee. Two additional samples were positive on a D-Screen test, but were not further specified by utilised typing kits. Five out of 6 determined D variant types from BTIS had c antigen, and they were typed as weak D - one sample serologically typed as Ccddee was weak D type 11, as well as 1 sample serologically typed as CcddEe; out of 3 samples serologically typed as ccddEe, 1 sample was weak D type 2 and 2 samples were weak D type 15 . One remaining $D$ variant sample from BTIS, originally serologically typed as CCddee, was found to be D-CE(2-9)$\mathrm{D}$ variant $\left(R H D^{*} 01 N .03\right)$. Four samples from ITMRS with weak D type 11 and all 5 samples with c antigen from BTIS were afterwards also serologically confirmed at BTIS using the adsorption/elution technique described above.

\section{Discussion}

These are the first results of studies determining the $\mathrm{RhD}$ variants by molecular typing and comparing the results of immunohematological and molecular testing at ITMRS and BTIS. Weak D types 1-3 are reportedly most frequent among weak $\mathrm{D}$ variants, representing about $93 \%$ of weak D variants in a Caucasian population $[3,22]$. Frequencies vary in different populations: very rare weak D type 38 is relatively common in the Portuguese population [23]; weak D type 42 is the most common in Quebec, Canada [24], whereas weak D type 3 is the most common in the Zagreb region of Croatia [25]. This study demonstrates that among initially serologically determined weak D donors at ITMRS, there is a majority of weak D type 3 (58.8\%), followed by weak D type $1(35.3 \%)$ and DNB (1.2\%), while at BTIS more diversity was found with weak $D$ type 1 being the most frequent (41.9\%), followed by weak D type 3 (30.7\%), weak D type 14 (6.5\%), weak D type $15(1.6 \%)$, and DNB (1.6\%). In 11 cases $(17.7 \%)$ of total serologically determined weak D types at BTIS, molecular typing showed presumable standard D $\left(R H D^{*} 01\right)$ results as the combination of molecular tests used could not discriminate between standard D and some rare $R H D$ variants. The results from ITMRS are more comparable to those from the neighbouring country of Croatia [25] than the results from BTIS. This could stem from historical migrations and gene pool exchange 
between populations in these areas of Southeastern Europe.

Serologically weak D phenotype is defined as reactivity of RBCs with an anti-D reagent giving no or weak $(\leq 2+)$ reactivity in initial testing, but agglutinating moderately or strongly with anti-human globulin [26-28]. An antiglobulin test for the detection of some weaker forms of $\mathrm{D}$ variant phenotypes is not recommended for patient testing in the UK [29], France, Germany [30, 31], the Netherlands [32], or the USA [27], but it is mandatory in some countries in central Europe, for example Austria $[19,20]$. Both institutes which participated in this study adopted the abovementioned algorithm, as well as an indirect antiglobulin test by gel method for weak D variants.

All samples serologically typed as weak D from ITMRS were confirmed by molecular typing as weak $\mathrm{D}$, whereas at BTIS there were 11 out of 62 samples initially serologically typed as weak D, which were later determined as standard D by molecular typing, as described above. For blood donors and newborns, it is a standard practice for laboratories to have policies and procedures for RhD typing to ensure that weak D phenotypes are detected serologically and interpreted as RhD positive [21-24]. Interpretation of agglutination strength for $\mathrm{RhD}$ antigen depends on variations in: (a) the strength of $\mathrm{D}$ antigen expression on some RBCs; (b) the test methods used; (c) the specificity of antibody clones and reagent formulations, and (d) interpretation [26-28]. These reasons could explain the discrepancy between results of serological and molecular typing at BTIS.

The occurrence of DNB variants is in correlation with other previously reported results [33], where it was shown as common partial D in Central Europe. The most frequent haplotype for $\mathrm{DNB}$ is $\mathrm{CDe}$, which should also be the case in our results, considering the phenotypes (CcDee, CCDee) and haplotype frequencies [8]. Since DNB antigen can serologically react like standard D (as did the sample from BTIS) [33], it was not possible to make that differentiation without using molecular typing of the samples.

Inability to detect $\mathrm{D}$ variants by immunohematological techniques has been reported by several authors from various countries [33-36]. RhD variants are detected in D-negative, C- and/or E-positive blood donors [20]. In some European countries and Australia, it is recommended to use an indirect antiglobulin test in C- and/or E-positive donors in order to minimise the risk of alloimmunisation to $\mathrm{RhD}$ variants in $\mathrm{D}$-negative recipients, as well as costs and time-consuming testing $[19,36]$. The results shown here indicated that, in spite of implementing indirect antiglobulin tests in routine detection of $\mathrm{D}$ variants, 9/92 initially serologically $\mathrm{RhD}$-negative donors from ITMRS showed RHD presence by molecular typing, as well as 6/61 individuals from BTIS, which represents about $9.8 \%$ from the total number of $\mathrm{D}$-negative, $\mathrm{C} / \mathrm{E}$ positive tested samples from each institute.

It should be emphasised that most results shown here as "weak D type 11" from both institutes (with the possible exception of CcEe sample from BTIS), could probably be designated as $R H D(M 295 I)$, which has a borderline $\mathrm{D}$ weak/DEL phenotype, and is typically detected in the CDe haplotype [37]. As typing software cannot separate haplotypes, its designation "weak D type 11 " was merely a confirmation of the $885 \mathrm{G}>\mathrm{T}$ mutation. Due to haplotype frequencies in Caucasian populations, it seems much more probable that in Ccee phenotypes, found in 5 out of 6 of these variants, the mutation $885 \mathrm{G}>\mathrm{T}$ (M295I) occurs as a DEL phenotype, rather than a weak D phenotype [8].

\section{Conclusion}

The Rh blood group molecular testing was successfully implemented at both of the blood transfusion institutes that participated in this study - from Banja Luka and Belgrade. The molecular testing used in this study also affirmed the current algorithm used for serological detection of weak D types in the population of blood donors. Serological methods depend on immunohematological technique and test reagents are not capable of always unequivocally detecting $\mathrm{RhD}$ variants (weak $\mathrm{D}$, such as weak D type 11, partial D or DEL) [38]. Therefore, RHD molecular typing is recommended to identify and confirm $R H D$ variants [39]. Transfusion of D-positive RBCs to partial D individuals or the pregnancy of partial D women with D-positive fetuses could induce alloimmunisation against the missing epitopes $[3,8,33,36]$. A necessity emerges from this study to determine the frequency of $R H D$ alleles in these two populations on a much larger scale in order to improve overall RhD testing and to establish transfusion strategies for donor and prenatal testing in these countries and concurrently enhance its clinical relevance. This will avoid the unnecessary application of $\mathrm{RhD}$ immune globulins for pregnant women with weak D types 1, 2, and 3, and also the transfusion of RhDnegative component therapy to individuals with these $\mathrm{RhD}$ antigens, consequently establishing a better supply of $\mathrm{RhD}$-negative blood products. In conclusion, the results presented in this study suggest that mandatory molecular testing of $\mathrm{RhD}$-negative blood donors, at least those with $\mathrm{C}+$ and/or E+, as used in this research, would contribute to more precise, reliable, and cost-effective results, leading to safer blood transfusions, as shown previously in countries where this procedure is already mandatory [40]. 


\section{Acknowledgements}

The authors would like to acknowledge Jelena Istatkov, MD, and Ana Milic, MD, for their help in collecting blood samples from the donors included in this study, as well as Zorana Andric, MD, $\mathrm{PhD}$, and Sasenka Stankovic (all from BTIS) for their help in DNA extraction.

\section{Statement of Ethics}

Informed written consent was obtained from the participants, and the study was approved by the Ethics Board of the Clinical Centre of Banja Luka and Ethics Board of BTIS.

\section{Disclosure Statement}

M.L. is employed as a scientific advisor by a local distributor of Inno-Train Diagnostik, which was not involved in this study in any way, particularly scientifically, financially, or in writing the paper. All other authors declare no conflicts of interest.

\section{Funding Sources}

The research presented in this article was financed exclusively by the respective institutions where the research was conducted the Institute for Transfusion Medicine of Republika Srpska, Banja Luka, Bosnia-Herzegovina, and the Blood Transfusion Institute of Serbia, Belgrade, Serbia. No external funding or donations were provided for this research.

\section{Author Contributions}

G.G. - substantial contributions to conception and design, acquisition of data, analysis and interpretation of data, drafting the article, and final approval of the version to be published. S.J.S. substantial contributions to conception and design, acquisition of data, analysis and interpretation of data, drafting the article, revising it critically for important intellectual content, and final approval of the version to be published. N.P.J. - acquisition of data, analysis and interpretation of data. I.D. - acquisition of data, analysis and interpretation of data. M.L. - substantial contributions to conception and design, acquisition of data, analysis and interpretation of data, drafting the article, revising it critically for important intellectual content, and final approval of the version to be published.

\section{References}

1 International Society of Blood Transfusion [Internet]. Table of blood group antigens v.8 180620, 2018 [cited 2018 Oct 20]. Available from: http://www.isbtweb.org/fileadmin/user_upload/Red_Cell_Terminology_ and_Immunogenetics/Table_of_blood_ group_antigens_within_systems_v8_180620. pdf.

2 Okuda H, Suganuma H, Kamesaki T, Kumada M, Tsudo N, Omi T, et al. The analysis of nucleotide substitutions, gaps, and recombination events between RHD and RHCE genes through complete sequencing. Biochem Biophys Res Commun. 2000 Aug;274(3):670-83.

3 Daniels G. Variants of RhD-current testing and clinical consequences. Br J Haematol. 2013 May;161(4):461-70.

4 Wagner FF, Flegel WA. RHD gene deletion occurred in the Rhesus box. Blood. 2000 Jun; 95(12):3662-8.

5 Avent ND, Ridgwell K, Tanner MJ, Anstee DJ. cDNA cloning of a $30 \mathrm{kDa}$ erythrocyte membrane protein associated with Rh (Rhesus)blood-group-antigen expression. Biochem J. 1990 Nov;271(3):821-5.

6 Chérif-Zahar B, Bloy C, Le Van Kim C, Blanchard D, Bailly P, Hermand P, et al. Molecular cloning and protein structure of a human blood group Rh polypeptide. Proc Natl Acad Sci USA. 1990 Aug;87(16):6243-7.

7 Avent ND, Reid ME. The Rh blood group system: a review. Blood. 2000 Jan;95(2):375-87.

8 Daniels G. Human Blood Groups. 3rd ed. Oxford: Wiley; 2013. https://doi.org/10.1002/ 9781118493595.

9 Flegel WA. Molecular genetics and clinical applications for RH. Transfus Apheresis Sci. 2011 Feb;44(1):81-91.

10 Reid ME, Lomas-Francis C. The Blood Group Antigen Facts Book. 2nd ed. San Diego: Academic Press; 2003.
11 Denomme GA, Dake LR, Vilensky D, Ramyar L, Judd WJ. Rh discrepancies caused by variable reactivity of partial and weak $\mathrm{D}$ types with different serologic techniques. Transfusion. 2008 Mar;48(3):473-8.

12 Judd WJ, Moulds M, Schlanser G. Reactivity of FDA-approved anti-D reagents with partial D red blood cells. Immunohematology. 2005; 21(4):146-8.

13 Jenkins CM, Johnson ST, Bellissimo DB, Gottschall JL. Incidence of weak D in blood donors typed as D positive by the Olympus PK 7200. Immunohematology. 2005;21(4): 152-4.

14 Westhoff CM. Review: the Rh blood group D antigen... dominant, diverse, and difficult. Immunohematology. 2005;21(4):155-63.

15 Credidio DC, Pellegrino J Jr, Castilho L. Serologic and molecular characterization of $\mathrm{D}$ variants in Brazilians: impact for typing and transfusion strategy. Immunohematology. 2011;27(1):6-11.

16 Legler TJ, Maas JH, Köhler M, Wagner T, Daniels GL, Perco P, et al. RHD sequencing: a new tool for decision making on transfusion therapy and provision of $\mathrm{Rh}$ prophylaxis. Transfus Med. 2001 Oct;11(5):383-8.

17 Garratty G. Do we need to be more concerned about weak D antigens? Transfusion. 2005 Oct;45(10):1547-51.

18 Wagner FF, Frohmajer A, Ladewig B, Eicher NI, Lonicer CB, Müller TH, et al. Weak D alleles express distinct phenotypes. Blood. 2000 Apr;95(8):2699-708.

19 Engelfriet CP, Reesink HW. Testing for weak D. Vox Sang. 2006 Feb;90(2):140-53.

20 Gassner C, Doescher A, Drnovsek TD, Rozman P, Eicher NI, Legler TJ, et al. Presence of RHD in serologically D-, C/E+ individuals: a European multicenter study. Transfusion. 2005 Apr;45(4):527-38.
21 Judd WJ, Johnson ST, Storry J. Judd's methods in immunohematology. 3rd ed. Bethesda (MD): AABB Press; 2008.

22 Wagner FF, Gassner C, Müller TH, Schönitzer D, Schunter F, Flegel WA. Molecular basis of weak D phenotypes. Blood. 1999 Jan;93(1): 385-93.

23 Araújo F, Rodrigues MJ, Monteiro F, Chabert T, Tavares G, Sousa G, et al. Weak D type 2 is the most prevalent weak D type in Portugal. Transfus Med. 2006 Feb;16(1):63-7.

24 St-Louis M, Richard M, Côté M, Éthier C, Long A. Weak D type 42 cases found in individuals of European descent. Immunohematology. 2011;27(1):20-4.

25 Dogic V, Bingulac-Popovic J, Babic I, Hundric-Haspl Z, Jurakovic-Loncar N, Mratinovic-Mikulandra J, et al. Distribution of weak D types in the Croatian population. Transfus Med. 2011 Aug;21(4):278-9.

26 Johnson ST. Partial D \& weak D: picking up the Rhesus pieces. Milwaukee: Heart of America Association of Blood Banks; 2012 April 24.

27 Sandler SG, Flegel WA, Westhoff CM, Denomme GA, Delaney M, Keller MA, et al.; College of American Pathologists Transfusion Medicine Resource Committee Work Group. It's time to phase in RHD genotyping for patients with a serologic weak D phenotype. Transfusion. 2015 Mar;55(3):680-9.

28 Agre PC, Davies DM, Issitt PD, Lamy BM, Schmidt PJ, Treacy M, et al. A proposal to standardize terminology for weak D antigen. Transfusion. 1992 Jan;32(1):86-7.

29 Fung MK, Grossman BJ, Hillyer CD, Westhoff CM, editors. Technical Manual 18. Bethesda (MD): AABB; 2014. 
30 Mota M, Fonseca NL, Rodrigues A, Kutner JM, Castilho L. Anti-D alloimmunization by weak D type 1 red blood cells with a very low antigen density. Vox Sang. 2005 Feb;88(2): 130-5.

31 Milkins C, Berryman J, Cantwell C, Elliott C, Haggas R, Jones J, et al.; British Committee for Standards in Haematology. Guidelines for pre-transfusion compatibility procedures in blood transfusion laboratories. Transfus Med. 2013 Feb;23(1):3-35

32 de Vries R, Haas F; working group for revision of the Dutch Blood Transfusion Guideline 2011. English translation of the dutch blood transfusion guideline 2011. Clin Chem. 2012 Aug;58(8):1266-7.
33 Wagner FF, Eicher NI, Jørgensen JR, Lonicer CB, Flegel WA. DNB: a partial D with anti-D frequent in Central Europe. Blood. 2002 Sep; 100(6):2253-6.

34 Opoku-Okrah C, Amidu N, Amoah-Sakyi S. Detection of weak $\mathrm{D}(\mathrm{Du})$ phenotype among Rh-D negative males and females in Kumasi, Ghana. J Sci Technol. 2008;28:34-40.

35 Hussein E, Teruya J. Weak D types in the Egyptian population. Am J Clin Pathol. 2013 Jun;139(6):806-11.

36 El Wafi M, El Housse H, Nourichafi N, Bouisk K, Benajiba M, Habti N. Prevalence of weak D phenotype among $\mathrm{D}$ negative $\mathrm{C} / \mathrm{E}+$ blood donors in Morocco. Int J Blood Transfus Immunohematol. 2016;6:3-7.
37 Wagner FF, Flegel WA. The Rhesus site. Transfus Med Hemother 2014;41(5):357363. http://www.rhesusbase.info/.

38 Sandler SG, Chen LN, Flegel WA. Serological weak D phenotypes: a review and guidance for interpreting the RhD blood type using the RHD genotype. Br J Haematol. 2017 Oct; 179(1):10-9.

39 Ouchari M, Srivastava K, Romdhane H, Jemni Yacoub S, Flegel WA. Transfusion strategy for weak D Type 4.0 based on RHD alleles and RH haplotypes in Tunisia. Transfusion. 2018 Feb;58(2):306-12.

40 Crottet SL, Henny C, Meyer S, Still F, Stolz M, Gottschalk J, et al. Implementation of a mandatory donor RHD screening in Switzerland. Transfus Apheresis Sci. 2014 Apr;50(2):16974. 